\title{
Spirometry-Adjusted Fraction of Exhaled Nitric Oxide Allows Asthma Diagnosis in Children, Adolescents, and Young Adults
}

\author{
Tomasz Grzelewski MD PhD, Włodzimierz Stelmach MD PhD, Rafał Stelmach, \\ Anna Janas MD PhD, Aleksandra Grzelewska MSc, Konrad Witkowski MD, \\ Eusebio Makandjou-Ola MD PhD, Paweł Majak MD PhD, and Iwona Stelmach MD PhD
}

\begin{abstract}
BACKGROUND: Recently, it has been proved that fractional exhaled nitric oxide $\left(\mathbf{F}_{\text {ENO }}\right)$ results are in disagreement with other measurements of asthma control. The objective of this work is to present and validate new lung function/lung inflammation ratios. METHODS: This is a retrospective, cross-sectional study in which we evaluated data from medical documentation of 1,529 pediatric and adolescent subjects and a small number (2\% of the studied population) of young adults, who presented symptoms suggestive of asthma (age range 4-24 y). We are the first to analyze results obtained in this manner (before the introduction of controlled medication): $\mathbf{F}_{\mathrm{ENO}}$, spirometry, specific resistance of the airways, diagnosis of allergic diseases, and allergen sensitization (specific immunoglobulin E results). RESULTS: Cut-off points for the new indicators allowed us to diagnose asthma in the study participants: for $F V C / F_{E N O}$ ratio, $0.17 \mathrm{~L} / \mathrm{ppb}$; for $F E V_{1} / F_{E N O}$ ratio, $0.15 \mathrm{~L} / \mathrm{ppb}$; for forced expiratory flow during the middle half of the $\mathrm{FVC}$ maneuver $\left(\mathrm{FEF}_{25-75 \%}\right) / \mathrm{F}_{\mathrm{ENO}}$ ratio, $0.16 \mathrm{~L} / \mathrm{s} / \mathrm{ppb}$; for $\mathrm{F}_{\mathrm{ENO}} / \mathrm{FVC}$ ratio, $11.00 \mathrm{ppb} / \mathrm{L}$; for $\mathrm{F}_{\mathrm{ENO}} / \mathrm{FEV}_{1}$ ratio, $12.53 \mathrm{ppb} / \mathrm{L}$; and for $\mathrm{F}_{\mathrm{ENO}} / \mathrm{FEF}_{25-75 \%}$ ratio, $11.81 \mathrm{ppb} / \mathrm{L} / \mathrm{s}$. Only the ratios described above were closely correlated with the diagnosis of asthma and with one another. They significantly differed between subjects with asthma and healthy subjects as well as between females and males. Only $\mathbf{F E F}_{25-75 \%} / \mathrm{F}_{\text {ENO }}$ and $\mathbf{F}_{\mathbf{E N O}} / \mathbf{F E F}_{25-75 \%}$ values were significant predictors of any sensitization in the studied subjects. We found higher sensitivity than specificity and higher positive predictive value than negative predictive value for $\mathrm{FVC} / \mathrm{F}_{\mathrm{ENO}}, \mathrm{FEV}_{\mathbf{1}} / \mathrm{F}_{\mathrm{ENO}}$, and $\mathrm{FEF}_{25-75 \%} / \mathrm{F}_{\mathrm{ENO}}$ and found a mirror image for reverse parameters. However, the positive predictive values and negative predictive values were not clearly convincing with respect to diagnostic accuracy in the case of the new parameters proposed. CONCLUSIONS: We propose new lung function/lung inflammation ratios by which it may become possible to diagnose asthma in children and adolescents on the basis of a subject's spirometry and $\mathbf{F}_{\text {ENO }}$ measurements. We believe that our ratios are only supportive of the universally used parameters in the process of diagnosing asthma. (ClinicalTrials.gov registration NCT01805635.) Key words: nitric oxide; respiratory function; asthma diagnosis; children; young adults. [Respir Care 2016;61(2):162-172. @ 2016 Daedalus Enterprises]
\end{abstract}

\section{Introduction}

The current concept of asthma pathogenesis underlines a chronic inflammatory process that causes air flow ob-

\footnotetext{
Drs Grzelewski and Iwona Stelmach are affiliated with the Departments of Pediatrics and Allergy, N. Copernicus Hospital, Medical University of Lodz, Lodz, Poland. Dr Grzelewski is also affiliated with the Atlantic Clinic LTD, Southampton, Hampshire, United Kingdom. Dr Włodzimierz Stelmach is affiliated with the Department of Social and Preventive Medicine, Medical University of Lodz, Lodz, Poland. Mr Rafał Stelmach
}

struction and bronchial hyper-responsiveness (AHR). ${ }^{1}$ The exact role of nitric oxide (NO) in the airways and lungs is multifaceted. ${ }^{2-4}$ On the one hand, it may act as a pro- 
inflammatory mediator predisposing to the development of AHR, whereas, on the other hand, under physiological conditions, it acts as a weak mediator of smooth muscle relaxation and protects against AHR..$^{2-7}$ Recently, it has been proved that fractional exhaled nitric oxide $\left(\mathrm{F}_{\mathrm{ENO}}\right)$ results are in disagreement with other measurements of asthma control in children, namely spirometry, children's asthma control test, and conventional clinical assessment. ${ }^{8}$ Green et $\mathrm{al}^{8}$ showed that mean $\mathrm{F}_{\mathrm{ENO}}$ in pediatrician-judged uncontrolled asthma was double that in controlled asthma. $\mathrm{F}_{\mathrm{ENO}}$ correlates with bronchial reactivity ${ }^{9}$ and decreases when anti-inflammatory asthma therapy in children is used. ${ }^{10} \mathrm{~F}_{\mathrm{ENO}}$ values can be affected by several factors. ${ }^{2}$ Pediatricians and allergists expect that $\mathrm{F}_{\mathrm{ENO}}$ is an inflammometer but not a lung function indicator. We are aware of the fact that most children with asthma have normal $\mathrm{FEV}_{1}$ outside of acute attacks; however, so far, only in one study (Grzelewski et al. $)^{11}$ has the influence of a degree of baseline bronchial constriction on $\mathrm{F}_{\mathrm{ENO}}$ results in children been assessed. ${ }^{11} \mathrm{We}$ found that, independently of the influence of $\mathrm{FEV}_{1}$ on $\mathrm{F}_{\mathrm{ENO}}$, such a relationship has obvious clinical implications that create the need to measure $\mathrm{F}_{\mathrm{ENO}}$ before as well as after spirometry and, consequently, in children with asthma with bronchial obstruction to assess $\mathrm{F}_{\mathrm{ENO}}$ also after the administration of short-acting $\beta_{2}$ agonists. ${ }^{11}$ We emphasized that it was reasonable to use the $\mathrm{F}_{\mathrm{ENO}} / \mathrm{FEV}_{1}$ ratio, which could overcome doubts concerning the adequate measurement of inflammation by $\mathrm{F}_{\mathrm{ENO}}{ }^{11}$ These results were the reason to perform the current analyses; we aimed at presenting and validating new lung function/lung inflammation ratios that adjust inflammatory $\mathrm{F}_{\mathrm{ENO}}$ to, especially, $\mathrm{FEV}_{1}, \mathrm{FVC}, \mathrm{FEF}_{25-75 \%}$, respiratory resistance measured by the interrupter technique, and specific airway resistance $\left(\mathrm{R}_{\mathrm{aw}}\right)$ values in children, adolescents, and young adults with asthma and other allergic diseases in the context of sex, specific immunoglobulin $\mathrm{E}$ (IgE) values, and the occurrence of allergic illness. We were inclined to test hypotheses that the ratios between $\mathrm{F}_{\mathrm{ENO}}$ and lung function parameters $\left(\mathrm{eg}, \mathrm{F}_{\mathrm{ENO}} / \mathrm{FVC}\right.$, $\mathrm{F}_{\mathrm{ENO}} / \mathrm{FEV}_{1}$, etc) would be useful in differentiating between subjects with asthma and subjects without asthma. The idea behind this research was to calculate the parameters in a relatively large number of children and adoles-

Poland. Dr Majak is affiliated with the Department of Internal Medicine, Asthma and Allergy, Medical University of Lodz, Lodz, Poland.

The authors have disclosed no conflicts of interest.

Correspondence: Iwona Stelmach MD PhD, Department of Paediatrics and Allergy, Medical University of Lodz, N. Copernicus Memorial Hospital, 71 Al. Pilsudskiego 90-329 Lodz, Poland. E-mail: alergol@kopernik.lodz.pl.

DOI: $10.4187 /$ respcare.04092

\section{QUICK LOOK}

\section{Current knowledge}

Asthma is a chronic inflammatory process that causes airflow obstruction and bronchial hyper-responsiveness. Exhaled nitric oxide concentrations $\left(\mathrm{F}_{\mathrm{ENO}}\right)$ have been shown to increase in lung inflammation and decrease following successful anti-inflammatory treatment of asthma in children. A number of factors alter $\mathrm{F}_{\mathrm{ENO}}$, and the use of $\mathrm{F}_{\mathrm{ENO}}$ to monitor lung inflammation requires consideration of a host of physiologic considerations and clinician expertise.

\section{What this paper contributes to our knowledge}

Using a ratio of $\mathrm{FEV}_{1}$ to $\mathrm{F}_{\mathrm{ENO}}$ successfully identified subjects with asthma compared with controls. The use of $\mathrm{F}_{\mathrm{ENO}}$ /spirometry ratios provides confirmatory evidence, but physical examination, history, spirometry, and peak flow measurements remain the hallmarks of asthma diagnosis.

cents and a very small number of young adults with asthma-like symptoms, who turned up for diagnostic evaluation at our specialist clinic.

\section{Methods}

\section{Study Design}

This was a retrospective, cross-sectional study. We evaluated data from the medical documentation of 1,529 children, adolescents, and young adults (age 4-24 y) with symptoms suggestive of asthma, who attended our allergy out-patient clinic from January 2005 to December 2012.

\section{Inclusion Criteria}

We included in the analyses subjects with a minimum of $4 \mathrm{y}$ of clinical observation, whose asthma was either confirmed or excluded. We only included those subjects who had all of the tests performed: $\mathrm{F}_{\mathrm{ENO}}$, respiratory resistance measured by the interrupter technique, whole-body plethysmography, spirometry, and specific IgE results with the following process.

In children naive to therapy, we performed all pulmonary function tests at the first visit on 1 day when they were naive to any anti-asthma therapy. We had checked their status when reviewing records in 2005-2008 before tests were performed. Henceforth we have been observing the children's records for a minimum of $4 \mathrm{y}$ after that point of the study, and we rechecked their asthma diagnosis 
status (confirmation or reject) in their medical records in 2009-2012. The subjects were chosen from the 20052008 population. Their results taken from the medical records were rechecked in 2009-2012. That is why we stated they had been observed for at least $4 \mathrm{y}$; the dates of pulmonary function testing were the years 2005-2008.

We emphasize that not all study subjects provided the researchers with complete results that were required for an exhaustive statistical analysis. Missing data, when encountered, were casewise deleted. Relevant result tables display exact numbers of study participants who provided reliable results. The diagnoses of asthma, allergic rhinitis, and atopic dermatitis have been universally established by allergy specialists according to the standard definitions of diseases in the latest guidelines ${ }^{1,12,13}$ or previous versions, respectively (due to the fact that the subjects had been admitted since January 2005). The diagnosis of asthma was made by allergy specialists based on the symptoms of asthma, the findings of the respiratory system physical examination, and an improvement in the pre-bronchodilator $\mathrm{FEV}_{1} \geq 12 \%$ and $200 \mathrm{~mL}$ after the administration of salbutamol $(200 \mu \mathrm{g})$ in all subjects. ${ }^{1}$ All parents and subjects were asked questions to consider within the diagnosis of asthma, according to the Global Initiative for Asthma (GINA) standard. ${ }^{1}$ The subjects' medical records were analyzed by allergist doctors who paid special attention to the initial results of $\mathrm{F}_{\mathrm{ENO}}$, respiratory resistance measured by the interrupter technique, whole-body plethysmography, spirometry, asthma diagnosis, allergic rhinitis diagnosis, and atopic dermatitis diagnosis as well as allergen sensitization (specific IgE results). The standard sequential procedure in our allergy out-patient clinic is as follows: $\mathrm{F}_{\mathrm{ENO}}$, respiratory resistance measured by the interrupter technique, whole body plethysmography, and spirometry. All of the lung function testing was conducted only on clinically stable subjects who were able to provide reproducible measurements of $\mathrm{F}_{\mathrm{ENO}}$, respiratory resistance measured by the interrupter technique, whole-body plethysmography, and spirometry. All of these tests were taken on the same day with a view of the differential diagnosis of asthma. The healthy group consisted of subjects without a history of asthma, allergic rhinitis, or atopic dermatitis and who were free from other illnesses; these subjects were non-asthmatic and non-atopic; none had respiratory tract symptoms or were treated with any drug in the 2 months preceding the evaluation of results; none of the subjects was chronically treated with inhaled corticosteroids and/or leukotriene inhibitors, which could mask asthma. The same data extractors assessed both the chart diagnosis of asthma and the related test data.

\section{Exclusion Criteria}

We excluded from the analyses subjects who did not have all of the tests performed: $\mathrm{F}_{\mathrm{ENO}}$, respiratory resistance measured by the interrupter technique, whole-body plethysmography, spirometry, and specific IgE results.

\section{Ethics}

The study was approved by the Medical Ethics Committee of the Medical University of Lodz. All the underage subjects' parents or guardians and adult subjects gave oral and written consent for the evaluation of data from their medical documentation.

\section{Detailed Information on Procedures}

Detailed information on the methods employed is available in our previous papers ${ }^{3,4,11}$ and in other authors' publications. ${ }^{14-22}$

\section{Statistics}

The statistical analyses of the findings were grounded on the following tests of significance: the D'Agostino omnibus test for normality, the Levene robust test statistic (estimating the homogeneity of variance), discriminant analysis (cutoff points were computed as weighted averages), the Mann-Whitney-Wilcoxon rank-sum test, the Pearson product-moment correlation coefficient, the Pearson chi-square test of independence, binary logistic regression, and generalized linear models. The nature of the data collected, along with the authors' inquisitiveness and inventive approach to the research problem, are the rationale behind their decisions about various statistical procedures.

In order to group, in a statistical sense, the study participants into a community of subjects diagnosed as having asthma versus healthy subjects, the discriminant analysis was performed. In the course of the aforementioned analysis, we referred to the new indicators (ratios) never previously analyzed in the literature, namely: $\mathrm{FVC} / \mathrm{F}_{\mathrm{ENO}}$ (L/ppb), $\quad \mathrm{FEV}_{1} / \mathrm{F}_{\mathrm{ENO}}(\mathrm{L} / \mathrm{ppb}), \quad \mathrm{FEF}_{25-75 \%} / \mathrm{F}_{\mathrm{ENO}}(\mathrm{L} / \mathrm{s} / \mathrm{ppb})$, $\mathrm{F}_{\mathrm{ENO}} / \mathrm{FVC}(\mathrm{ppb} / \mathrm{L}), \mathrm{F}_{\mathrm{ENO}} / \mathrm{FEV}_{1}(\mathrm{ppb} / \mathrm{L})$, and $\mathrm{F}_{\mathrm{ENO}} / \mathrm{FEF}_{25-75 \%}$ $(\mathrm{ppb} / \mathrm{L} / \mathrm{s})$.

The discussed discriminant analysis enabled us to determine that specified ratios (indicators) differentiated the subjects in terms of the diagnosis of asthma. We aimed at showing cutoff points, calculated in this area as weighted averages, with their SE values and confidence intervals, thanks to which it became possible to diagnose asthma on the basis of spirometry and $\mathrm{F}_{\mathrm{ENO}}$ results.

For the statistical analyses, we used Stata/Special Edition 12.1 for Windows (StataCorp, College Station, 
Table 1. Descriptive Statistics for the Analyzed Parameters in the Study Subjects

\begin{tabular}{|c|c|c|c|c|c|c|c|}
\hline \multirow{2}{*}{ Ratio } & \multicolumn{7}{|c|}{ Statistical Parameters } \\
\hline & $n$ & Median & Q1-Q3 & IQR & SE & $95 \% \mathrm{CI}$ & $\mathrm{CV}, \%$ \\
\hline Age, y & 1,529 & 11.0 & $8.0-14.0$ & 6.00 & 0.1 & $11.0-11.4$ & 35.0 \\
\hline BMI, $\mathrm{kg} / \mathrm{m}^{2}$ & 930 & 16.3 & $14.9-19.1$ & 4.2 & 0.1 & $17.1-17.5$ & 19.4 \\
\hline BMI, percentile & 894 & 57.9 & $29.2-86.5$ & 57.3 & 1.0 & $54.2-58.4$ & 55.6 \\
\hline $\mathrm{F}_{\mathrm{ENO}}, \mathrm{ppb}$ & 1,529 & 16.9 & $11.0-30.3$ & 19.3 & 0.7 & $24.7-27.3$ & 98.9 \\
\hline FVC, L & 975 & 1.8 & $1.5-2.3$ & 0.8 & 0.03 & $2.0-2.1$ & 47.6 \\
\hline $\mathrm{FEV}_{1}, \mathrm{~L}$ & 975 & 1.6 & $1.3-2.0$ & 0.7 & 0.03 & $1.8-1.9$ & 45.3 \\
\hline $\mathrm{FEF}_{25-75 \%}, \mathrm{~L} / \mathrm{s}$ & 975 & 1.8 & $1.4-2.4$ & 1.0 & 0.03 & $2.0-2.1$ & 48.8 \\
\hline Specific $\mathrm{R}_{\mathrm{aw}}, \mathrm{cm} \mathrm{H}_{2} \mathrm{O} \times \mathrm{s}$ & 537 & 10.1 & $8.4-12.2$ & 3.9 & 0.2 & $10.2-11.2$ & 50.1 \\
\hline $\begin{array}{l}\text { Respiratory resistance measured by the interrupter } \\
\text { technique, } \mathrm{cm} \mathrm{H}_{2} \mathrm{O} \times \mathrm{s} / \mathrm{L}\end{array}$ & 1,325 & 7.8 & $5.5-10.4$ & 4.9 & 0.1 & $8.3-8.7$ & 47.3 \\
\hline $\mathrm{FVC} / \mathrm{F}_{\mathrm{ENO}}, \mathrm{L} / \mathrm{ppb}$ & 975 & 0.12 & $0.08-0.19$ & 0.11 & 0.02 & $0.14-0.20$ & 282.7 \\
\hline $\mathrm{FEV}_{1} / \mathrm{F}_{\mathrm{ENO}}, \mathrm{L} / \mathrm{ppb}$ & 975 & 0.11 & $0.07-0.17$ & 0.10 & 0.01 & $0.12-0.17$ & 257.6 \\
\hline $\mathrm{FEF}_{25-75 \%} / \mathrm{F}_{\mathrm{ENO}}, \mathrm{L} / \mathrm{s} / \mathrm{ppb}$ & 975 & 0.12 & $0.07-0.19$ & 0.12 & 0.01 & $0.14-0.18$ & 205.0 \\
\hline $\begin{array}{l}\text { Respiratory resistance measured by the interrupter } \\
\text { technique } / \mathrm{F}_{\mathrm{ENO}}, \mathrm{cm} \mathrm{H}_{2} \mathrm{O} \times \mathrm{s} / \mathrm{L} / \mathrm{ppb}\end{array}$ & 1,325 & 0.10 & $0.2-0.81$ & 0.61 & 0.1 & $0.61-0.92$ & 451.0 \\
\hline Specific $\mathrm{R}_{\mathrm{aw}} / \mathrm{F}_{\mathrm{ENO}}, \mathrm{cm} \mathrm{H}_{2} \mathrm{O} \times \mathrm{s} / \mathrm{ppb}$ & 537 & 0.61 & $0.41-1.02$ & 0.61 & 0.04 & $0.81-0.92$ & 105.8 \\
\hline $\mathrm{F}_{\mathrm{ENO}} / \mathrm{FVC}, \mathrm{ppb} / \mathrm{L}$ & 975 & 8.3 & $5.3-12.9$ & 7.6 & 0.3 & $10.4-11.6$ & 88.8 \\
\hline $\mathrm{F}_{\mathrm{ENO}} / \mathrm{FEV}_{1}, \mathrm{ppb} / \mathrm{L}$ & 975 & 9.3 & $6.0-14.4$ & 8.4 & 0.4 & $11.8-13.2$ & 88.9 \\
\hline $\mathrm{F}_{\mathrm{ENO}} / \mathrm{FEF}_{25-75 \%}, \mathrm{ppb} / \mathrm{L} / \mathrm{s}$ & 975 & 8.5 & $5.2-13.5$ & 8.3 & 0.4 & $11.1-12.5$ & 96.2 \\
\hline $\begin{array}{l}\mathrm{F}_{\mathrm{ENO}} \text { /respiratory resistance measured by the } \\
\text { interrupter technique, } \mathrm{ppb} / \mathrm{cm} \mathrm{H}_{2} \mathrm{O} \times \mathrm{s} / \mathrm{L}\end{array}$ & 1,325 & 239.7 & $128.5-493.6$ & 368.1 & 14.3 & $398.7-454.8$ & 122.2 \\
\hline $\mathrm{F}_{\mathrm{ENO}} /$ specific $\mathrm{R}_{\mathrm{aw}}, \mathrm{ppb} / \mathrm{cm} \mathrm{H}_{2} \mathrm{O} \times \mathrm{s}$ & 537 & 171.3 & $99.9-286.6$ & 186.6 & 11.2 & $221.3-264.1$ & 103.4 \\
\hline $\begin{array}{l}\mathrm{Q} 1-\mathrm{Q} 3=\text { first through third quartile } \\
\mathrm{IQR}=\text { interquartile range } \\
\mathrm{CV}=\text { coefficient of variation } \\
\mathrm{BMI}=\text { body mass index } \\
\mathrm{F}_{\mathrm{ENO}}=\text { fractional exhaled nitric oxide } \\
\mathrm{FEF}_{25-75 \%} \text { = forced expiratory flow during the middle half of the } \\
\mathrm{R}_{\mathrm{aw}}=\text { airway resistance }\end{array}$ & euver & & & & & & \\
\hline
\end{tabular}

Texas). A level of significance at $P<.05$ was con sidered statistically significant. Missing data were casewise deleted.

\section{Results}

We included in the analysis 1,529 pediatric, adolescent, and young adult subjects ( $2 \%$ out of the studied population), altogether 4-24 y old. Absolute numbers of subjects submitted to $\mathrm{F}_{\mathrm{ENO}}$, whole-body plethysmography, respiratory resistance measured by the interrupter technique, spirometry, and specific IgE testing may vary due to missing data encountered during the analysis (ie, not all subjects had a complete set of the above diagnostic tests). Among the study participants, 607 subjects were female $(39.7 \%)$ and 922 were male $(60.3 \%)$. Most of the descriptive data are presented in Table $1.59 .7 \%$ of the studied subjects had been diagnosed as having asthma, $47.5 \%$ were subjects with allergic rhinitis, $8.7 \%$ were individuals with atopic dermatitis, and $26.4 \%$ were healthy. We also put under surveillance $37.6 \%$ of sub- jects presenting 2 or more allergic diseases; $32.9 \%$ of the subjects had 2 allergic diseases, and $4.7 \%$ had 3 allergic diseases at issue. All of the study participants who suffered from any of the diseases mentioned above were subjects with some allergies. Subjects of preschool age constituted $3.3 \%(n=51)$, subjects of junior age were $73.6 \%(n=1,125)$, teenagers were $20.9 \%(n=319)$, and young adults were merely $2.2 \%(n=34)$ of the total number of study participants.

\section{Asthma Diagnosis}

Asthma was diagnosed in $54.5 \%$ of females $(n=331)$ and in $63.1 \%$ of males $(n=582)$ (odds ratio $=1.43$, 95\% CI: $1.16-1.76, P<.01)$. Table 2 shows cutoff points of the original indicators, by which it becomes possible to underpin the diagnosis of asthma on the basis of a subject's spirometry, $\mathrm{F}_{\mathrm{ENO}}$, and appropriate co-dependences $\left(\mathrm{FVC} / \mathrm{F}_{\mathrm{ENO}}\right.$, $\mathrm{FEV}_{1} / \mathrm{F}_{\mathrm{ENO}}, \mathrm{FEF}_{25-75 \%} / \mathrm{F}_{\mathrm{ENO}}, \mathrm{F}_{\mathrm{ENO}} / \mathrm{FVC}, \mathrm{F}_{\mathrm{ENO}} / \mathrm{FEV}_{1}$, and $\left.\mathrm{F}_{\mathrm{ENO}} / \mathrm{FEF}_{25-75 \%}\right)$. 
Table 2. Cutoff Points Due to the Analyzed Ratios in Study Subjects Diagnosed as Having Asthma Versus Those Not Having Asthma

\begin{tabular}{llc}
\hline \multicolumn{1}{c}{ Ratio } & \multicolumn{1}{c}{ Value } & $95 \% \mathrm{CI}$ \\
\hline $\mathrm{FVC} / \mathrm{F}_{\mathrm{ENO}}, \mathrm{L} / \mathrm{ppb}$ & $0.17 \pm 0.02$ & $0.14-0.20$ \\
$\mathrm{FEV}_{1} / \mathrm{F}_{\mathrm{ENO}}, \mathrm{L} / \mathrm{ppb}$ & $0.15 \pm 0.01$ & $0.12-0.17$ \\
$\mathrm{FEF}_{25-75 \%} / \mathrm{F}_{\mathrm{ENO}}, \mathrm{L} / \mathrm{s} / \mathrm{ppb}$ & $0.16 \pm 0.01$ & $0.14-0.18$ \\
$\mathrm{~F}_{\mathrm{ENO}} / \mathrm{FVC}, \mathrm{ppb} / \mathrm{L}$ & $11.0 \pm 0.3$ & $10.4-11.6$ \\
$\mathrm{~F}_{\mathrm{ENO}} / \mathrm{FEV}_{1}, \mathrm{ppb} / \mathrm{L}$ & $12.5 \pm 0.3$ & $11.8-13.2$ \\
$\mathrm{~F}_{\mathrm{ENO}} / \mathrm{FEF}_{25-75 \%}, \mathrm{ppb} / \mathrm{L} / \mathrm{s}$ & $11.8 \pm 0.4$ & $11.1-12.5$
\end{tabular}

Values shown are mean \pm SE

$\mathrm{F}_{\mathrm{ENO}}=$ fractional exhaled nitric oxide

$\mathrm{FEF}_{25-75 \%}=$ forced expiratory flow during the middle half of the FVC maneuver

\section{Correlations Among Indicators With Respect to Asthma Diagnosis}

Ratios that significantly discriminate the study subjects in terms of the diagnosis of asthma $\left(\mathrm{FVC} / \mathrm{F}_{\mathrm{ENO}}, \mathrm{FEV}_{1} / \mathrm{F}_{\mathrm{ENO}}\right.$, $\mathrm{FEF}_{25-75 \%} / \mathrm{F}_{\mathrm{ENO}}, \mathrm{F}_{\mathrm{ENO}} / \mathrm{FVC}, \mathrm{F}_{\mathrm{ENO}} / \mathrm{FEV}_{1}$, and $\left.\mathrm{F}_{\mathrm{ENO}} / \mathrm{FEF}_{25-75 \%}\right)$ very strongly correlated with one another, as illustrated in Figures 1 and 2. As we see in Figure 1, the relationships between the investigated ratios are in the linear character, and they do display positive (directly proportional) and very strong correlations. The absolute values of the correlation coefficients approach a value of 1 , whereas the level of statistical significance proves their mutual dependence. Indeed, the higher the coefficient, the greater the dispersion of individual measurements, which indicates a strong right-sided skewness and leptokurtic nature of a trait.

As we see in Figure 2, the ratios (in all of the cases analyzed, $P<.01)$ assume the shape of the so-called exponential decay $\left(y=a(1-b)^{x}\right)$. The higher the ratios expressed in $\mathrm{ppb} / \mathrm{L}$, the smaller the ratios expressed in $\mathrm{L} / \mathrm{ppb}$. The findings enable us to claim that the discussed ratios (ie, specific spirometry and $\mathrm{F}_{\mathrm{ENO}}$ measurements), especially since they are closely correlated to one another, should become a new complement to guidelines on the diagnosis of asthma in children, adolescents, and young adults.

\section{Cutoff Values in Subjects With Asthma Versus Healthy Subjects}

The cutoff point values for the ratios at issue in the subjects with asthma versus the healthy ones are presented in Table 3. These are the first such values in the literature, allowing us to differentiate between children, adolescents, and young adults diagnosed as having asthma versus healthy ones.

\section{Cutoff Values in Males Versus Females}

As shown in Figures 3 and 4, the cutoff points for males versus females, subjects diagnosed with asthma versus those without any discussed disease, differ significantly. This implies a willingness to accept different normative values for females and males. Moreover, Figure 3 indicates that the combination ratios of spirometry and $\mathrm{F}_{\mathrm{ENO}}$ seem to be more reflective of lung function values than each ratio itself.

\section{Correlations of Indicators With Specific IgE Values for Selected Allergens}

We found no allergic sensitization in $44.1 \%$ of subjects in general, including $43.0 \%$ of females and $44.8 \%$ of males (not significant). We found allergy in $55.9 \%$ of studied subjects, including $57.0 \%$ of females and $55.2 \%$ of males. A polyvalent allergy was revealed in $92.9 \%$ of studied subjects, including $92.5 \%$ of females and $93.1 \%$ of males (not significant). House dust mite sensitization was found in $37.7 \%$ of subjects; sensitization to molds was found in $27.9 \%$ of the subjects; animal dander sensitization was found in $21.3 \%$ of subjects; and in $13.1 \%$ of study subjects, other types of sensitization were revealed. The sensitization type did not differ by sex. The subjects' sex was not a significant predictor of multiple sensitization or of single sensitization for house dust mites, animal dander, and molds. Surprisingly, only $\mathrm{FEF}_{25-75 \%} / \mathrm{F}_{\mathrm{ENO}}$ and $\mathrm{F}_{\mathrm{ENO}} / \mathrm{FEF}_{25-75 \%}$ values were significant predictors of any sensitization in the studied subjects. These parameters differed significantly in the sensitized subjects versus the non-sensitized ones. $\mathrm{FEF}_{25-75 \%} / \mathrm{F}_{\mathrm{ENO}}$ values had the following characteristics when taking into account the sensitization at issue: $P<.01$; cutoff point, $0.14 \mathrm{~L} / \mathrm{ppb}$; $\mathrm{SE}=.003 \mathrm{~L} / \mathrm{ppb} ; 95 \% \mathrm{CI}: 0.13-0.15 \mathrm{~L} / \mathrm{ppb}$; sensitivity, 63.5\%; specificity, $39.8 \%$; positive predictive value, $57.0 \%$; negative predictive value, $46.4 \% . \mathrm{F}_{\mathrm{ENO}} / \mathrm{FEF}_{25-75 \%}$ $(\mathrm{ppb} / \mathrm{L} / \mathrm{s})$ values had the following characteristics: $P=.042$; cutoff point, $9.79 \mathrm{ppb} / \mathrm{L} ; \mathrm{SE}=.22 \mathrm{ppb} / \mathrm{L} ; 95 \% \mathrm{CI}$ : $9.37-$ $10.22 \mathrm{ppb} / \mathrm{L}$; sensitivity, $41.1 \%$; specificity, $64.8 \%$; positive predictive value, $59.8 \%$; negative predictive value, $46.3 \%$.

\section{Discriminating Power of the Cutoff Points}

We found high sensitivity and positive predictive value for $\mathrm{FVC} / \mathrm{F}_{\mathrm{ENO}}, \mathrm{FEV}_{1} / \mathrm{F}_{\mathrm{ENO}}$, and $\mathrm{FEF}_{25-75 \%} / \mathrm{F}_{\mathrm{ENO}}$ and results behaving as a mirror image in the case of reverse parameters (see Figs. 5 and 6 and Table 4). The positive predictive values and negative predictive values were not clearly convincing with respect to the original parameters' diagnostic accuracy (see Figs. 5 and 6 and Tables 4 and 5). 

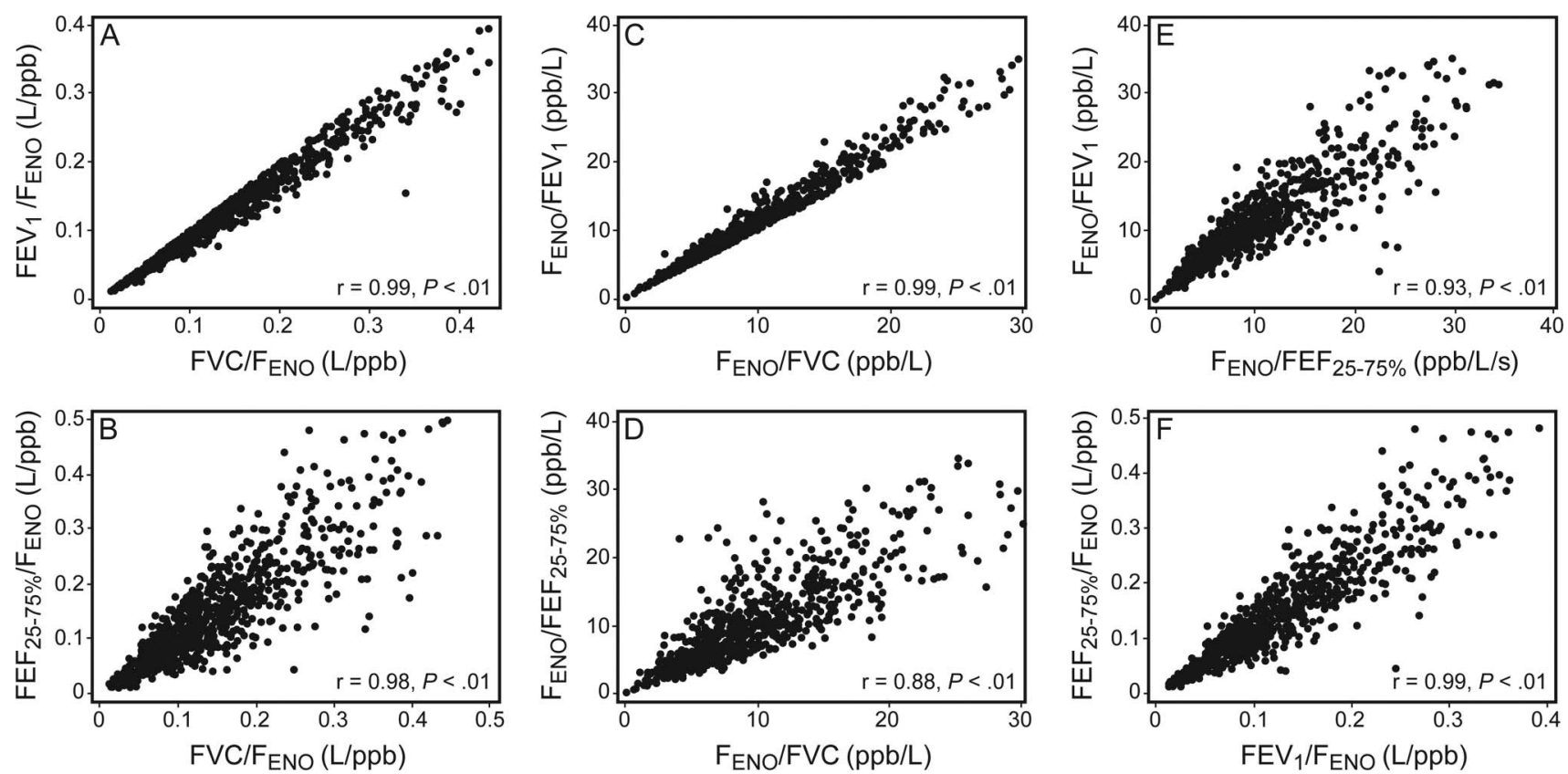

Fig. 1. Scatter plots illustrating positive correlations between selected spirometry and fractional exhaled nitric oxide $\left(\mathrm{F}_{\mathrm{ENO}}\right)$ results of the examined subjects with asthma.
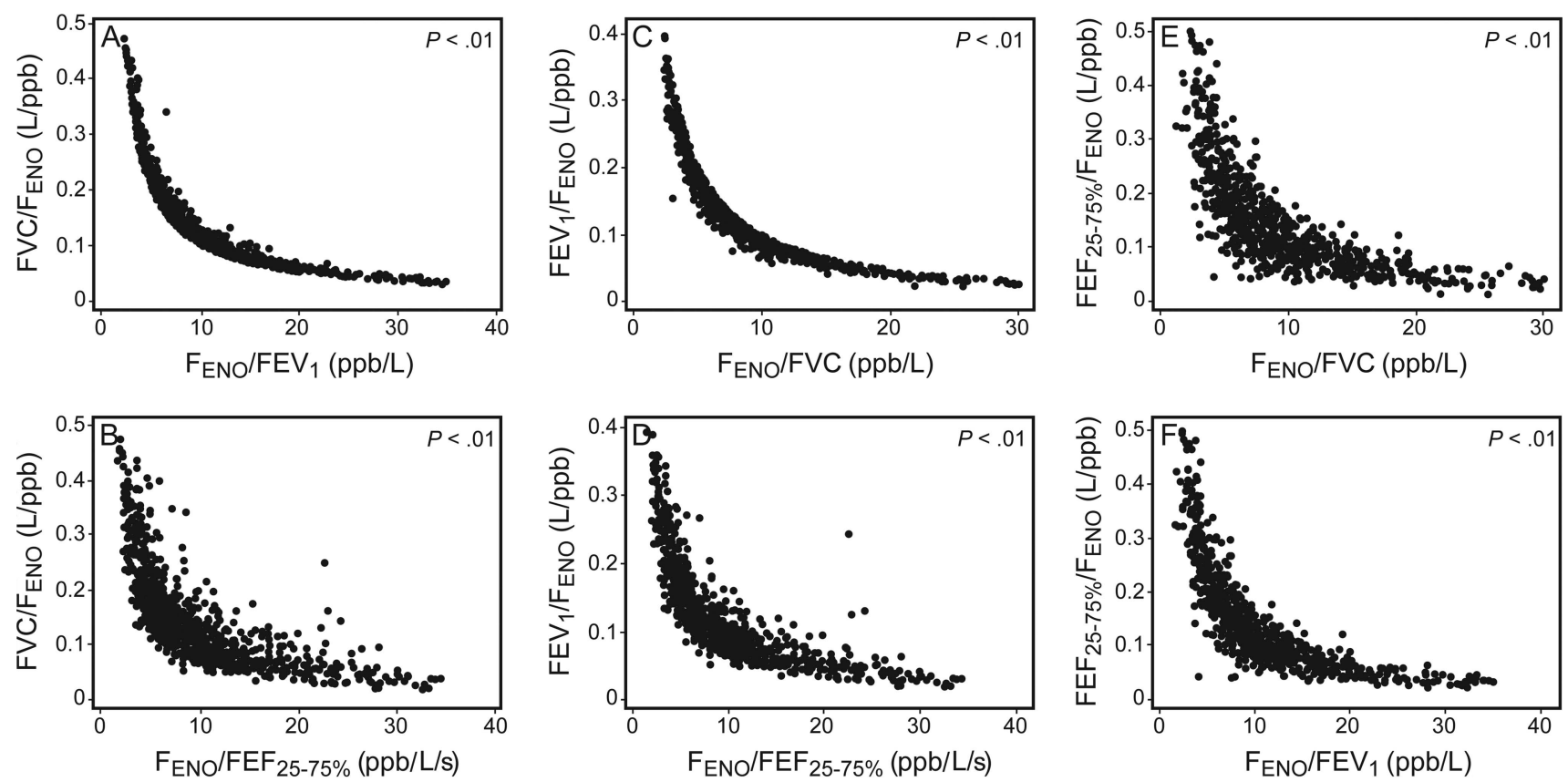

Fig. 2. Scatter plots showing exponential decay regarding the juxtaposition of selected spirometry and fractional exhaled nitric oxide $\left(\mathrm{F}_{\mathrm{ENO}}\right)$ results of the examined subjects with asthma.

Respiratory Resistance Measured by the Interrupter Technique and Specific $\mathbf{R}_{\mathrm{aw}}$ Correlations

Respiratory resistance measured by the interrupter technique and specific $\mathrm{R}_{\mathrm{aw}}$ correlations were not of any significance.

\section{Discussion}

Our study presents new and original ratios adjusting a lung inflammation parameter $\left(\mathrm{F}_{\mathrm{ENO}}\right)$ to the most important ventilation parameters of lung function that may allow us to distinguish between children, adolescents, and a small 
Spirometry-Adjusted F F For Asthma Diagnosis

Table 3. Descriptive Statistics for the Analyzed Ratios in Subjects Diagnosed as Having Asthma Versus Healthy Subjects

\begin{tabular}{|c|c|c|c|c|c|c|c|c|c|c|}
\hline \multirow{2}{*}{ Ratio } & \multicolumn{10}{|c|}{ Statistical Parameters } \\
\hline & Study Group $(n)$ & Mean & Median & Q1-Q3 & IQR & SD & SE & $95 \% \mathrm{CI}$ & $\mathrm{CV}, \%$ & Range \\
\hline \multicolumn{11}{|l|}{$\mathrm{FVC} / \mathrm{F}_{\mathrm{ENO}}$} \\
\hline Asthma & 570 & 0.15 & 0.12 & $0.07-0.18$ & 0.11 & 0.12 & 0.01 & $0.13-0.15$ & 82.9 & $0.01-1.29$ \\
\hline Healthy & 260 & 0.18 & 0.13 & $0.09-0.21$ & 0.12 & 0.16 & 0.01 & $0.16-0.20$ & 91.1 & $0.02-1.61$ \\
\hline \multicolumn{11}{|l|}{$\mathrm{FEV}_{1} / \mathrm{F}_{\mathrm{ENO}}$} \\
\hline Asthma & 570 & 0.13 & 0.10 & $0.06-0.16$ & 0.10 & 0.10 & 0.004 & $0.12-0.13$ & 81.7 & $0.01-1.13$ \\
\hline Healthy & 260 & 0.16 & 0.12 & $0.08-0.18$ & 0.10 & 0.14 & 0.01 & $0.14-0.17$ & 9.2 & $0.02-1.51$ \\
\hline \multicolumn{11}{|c|}{$\mathrm{FEF}_{25-75 \%} / \mathrm{F}_{\mathrm{ENO}}$} \\
\hline Asthma & 570 & 0.14 & 0.11 & $0.07-0.18$ & 0.11 & 0.12 & 0.01 & $0.13-0.15$ & 84.2 & $0.01-1.29$ \\
\hline Healthy & 260 & 0.18 & 0.13 & $0.09-0.22$ & 0.13 & 0.16 & 0.01 & $0.16-0.20$ & 91.0 & $0.01-1.75$ \\
\hline \multicolumn{11}{|l|}{$\mathrm{F}_{\mathrm{ENO}} / \mathrm{FVC}$} \\
\hline Asthma & 570 & 11.9 & 8.6 & $5.6-13.8$ & 8.2 & 1.8 & 0.4 & $11.0-12.8$ & 9.7 & $0.78-84.61$ \\
\hline Healthy & 260 & 9.2 & 7.6 & $4.9-11.3$ & 6.4 & 7.2 & 0.4 & $8.3-10.1$ & 77.9 & $0.62-52.78$ \\
\hline \multicolumn{11}{|l|}{$\mathrm{F}_{\mathrm{ENO}} / \mathrm{FEV}_{1}$} \\
\hline Asthma & 570 & 13.6 & 9.8 & $6.3-15.8$ & 9.5 & 12.4 & 0.5 & $12.6-14.6$ & 9.9 & $0.88-86.71$ \\
\hline Healthy & 260 & 1.4 & 8.6 & $5.5-13.1$ & 7.6 & 8.1 & 0.5 & $9.4-11.4$ & 77.6 & $0.66-61.93$ \\
\hline \multicolumn{11}{|c|}{$\mathrm{F}_{\mathrm{ENO}} / \mathrm{FEF}_{25-75 \%}$} \\
\hline Asthmatic & 570 & 13.0 & 9.0 & $5.6-15.3$ & 9.7 & 12.7 & 0.5 & $12.0-14.0$ & 97.9 & $0.78-87.06$ \\
\hline Healthy & 260 & 9.7 & 7.6 & $4.5-11.6$ & 7.1 & 8.5 & 0.5 & $8.6-1.7$ & 87.9 & $0.57-75.41$ \\
\hline $\begin{array}{l}\text { Q1-Q3 = first thr } \\
\text { IQR = interquarti } \\
\text { CV = coefficient } \\
\text { FENO }_{\text {ENactional }} \\
\text { FEF }_{25-75 \%}=\text { forc }\end{array}$ & $\begin{array}{l}\text { rd quartile } \\
\text { ion } \\
\text { nitric oxide } \\
\text { tory flow during the } \mathrm{n}\end{array}$ & alf of & mane & & & & & & & \\
\hline
\end{tabular}

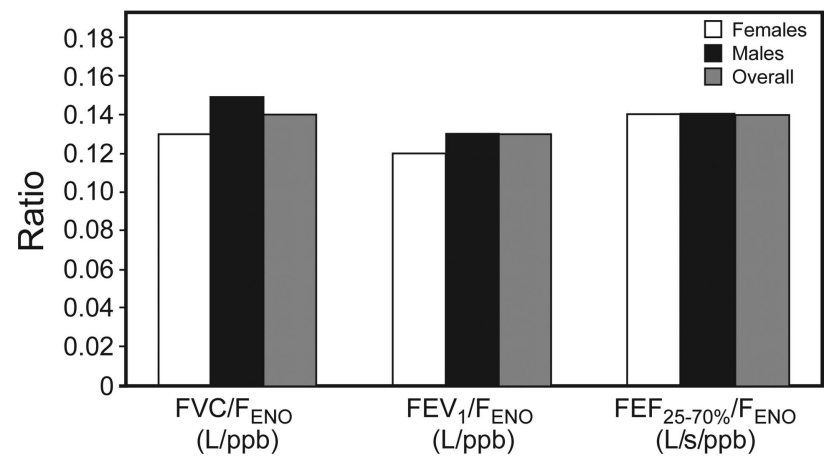

Fig. 3. The analyzed ratios' mean values in the study subjects with asthma by sex. $F_{E N O}=$ fractional exhaled nitric oxide.

number of young adults diagnosed as having asthma versus healthy persons. We revealed cutoff points of the original indicators, by which it becomes possible to underpin the diagnosis of asthma on the basis of a subject's spirometry, $\mathrm{F}_{\mathrm{ENO}}$, and appropriate co-dependences. The ratios that significantly discriminated the study subjects in terms of the diagnosis of asthma $\left(\mathrm{FVC} / \mathrm{F}_{\mathrm{ENO}}, \mathrm{FEV}_{1} / \mathrm{F}_{\mathrm{ENO}}\right.$, $\mathrm{FEF}_{25-75 \%} / \mathrm{F}_{\mathrm{ENO}}, \mathrm{F}_{\mathrm{ENO}} / \mathrm{FVC}, \mathrm{F}_{\mathrm{ENO}} / \mathrm{FEV}_{1}$, and $\left.\mathrm{F}_{\mathrm{ENO}} / \mathrm{FEF}_{25-75 \%}\right)$ very strongly correlated with one another. The cutoff points for males versus females, subjects diagnosed with asthma versus those who have not suffered from any discussed disease, did differ significantly. We re-

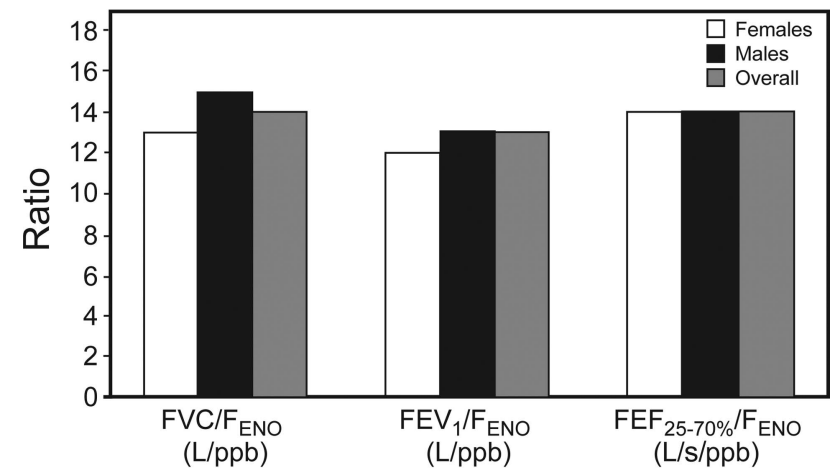

Fig. 4. The analyzed ratios' mean values in the study subjects with asthma by sex. $F_{E N O}=$ fractional exhaled nitric oxide.

vealed that only $\mathrm{FEF}_{25-75 \%} / \mathrm{F}_{\mathrm{ENO}}$ and $\mathrm{F}_{\mathrm{ENO}} / \mathrm{FEF}_{25-75 \%}$ were significant predictors of any sensitization in the studied subjects. We found higher sensitivity than specificity and higher positive predictive value than negative predictive value for $\mathrm{FVC} / \mathrm{F}_{\mathrm{ENO}}, \mathrm{FEV}_{1} / \mathrm{F}_{\mathrm{ENO}}$, and $\mathrm{FEF}_{25-75 \%} / \mathrm{F}_{\mathrm{ENO}}$ and a mirror image in terms of sensitivity/specificity for reverse parameters. To date, no study has suggested similar ratios; thus, it was impossible to compare our seminal results with the findings of other authors.

Our ideas closely correlate with the American Thoracic Society recommendations regarding the interpretations of $\mathrm{F}_{\mathrm{ENO}}$ results by Dweik et $\mathrm{al}^{2}$ and are rooted in our own 


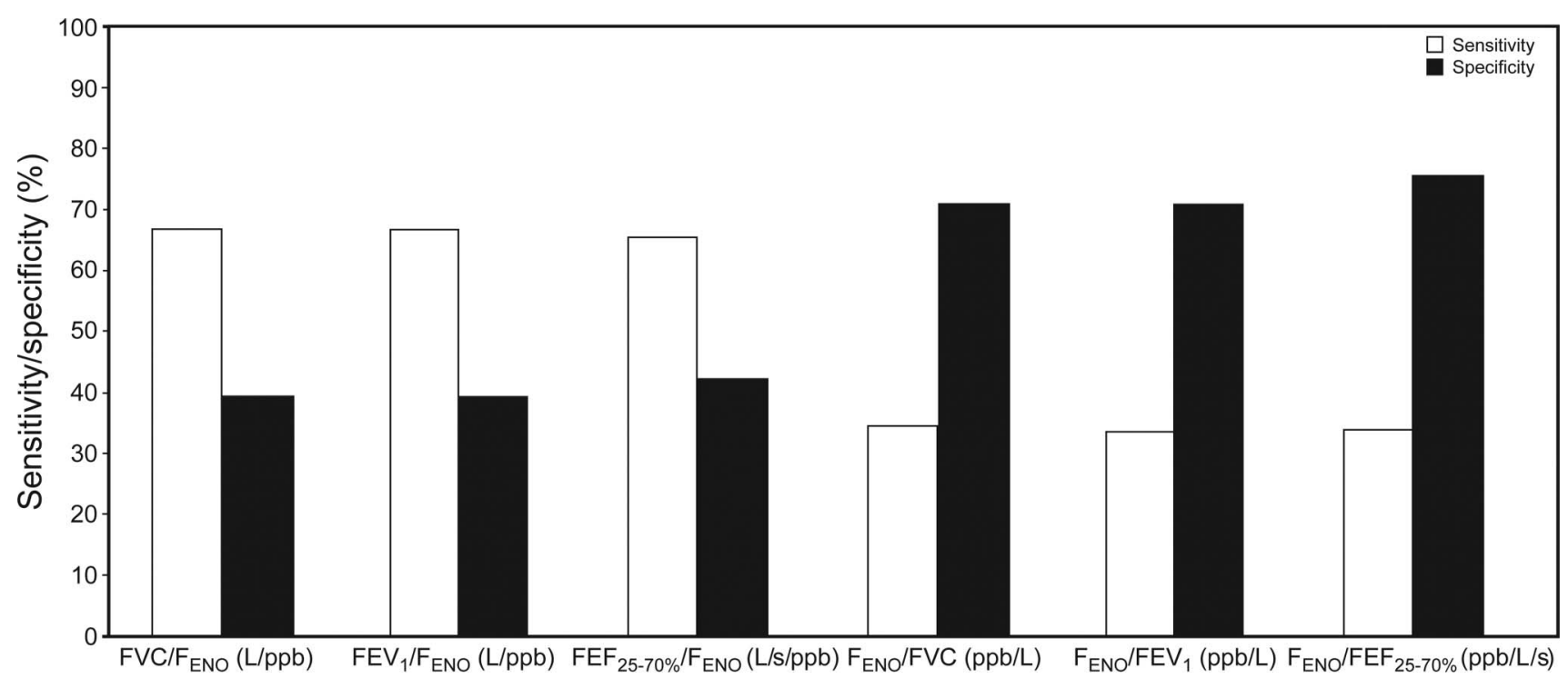

Fig. 5. Sensitivity and specificity values for significant cutoff points computed for the study subjects with asthma. $F_{E N O}=$ fractional exhaled nitric oxide.

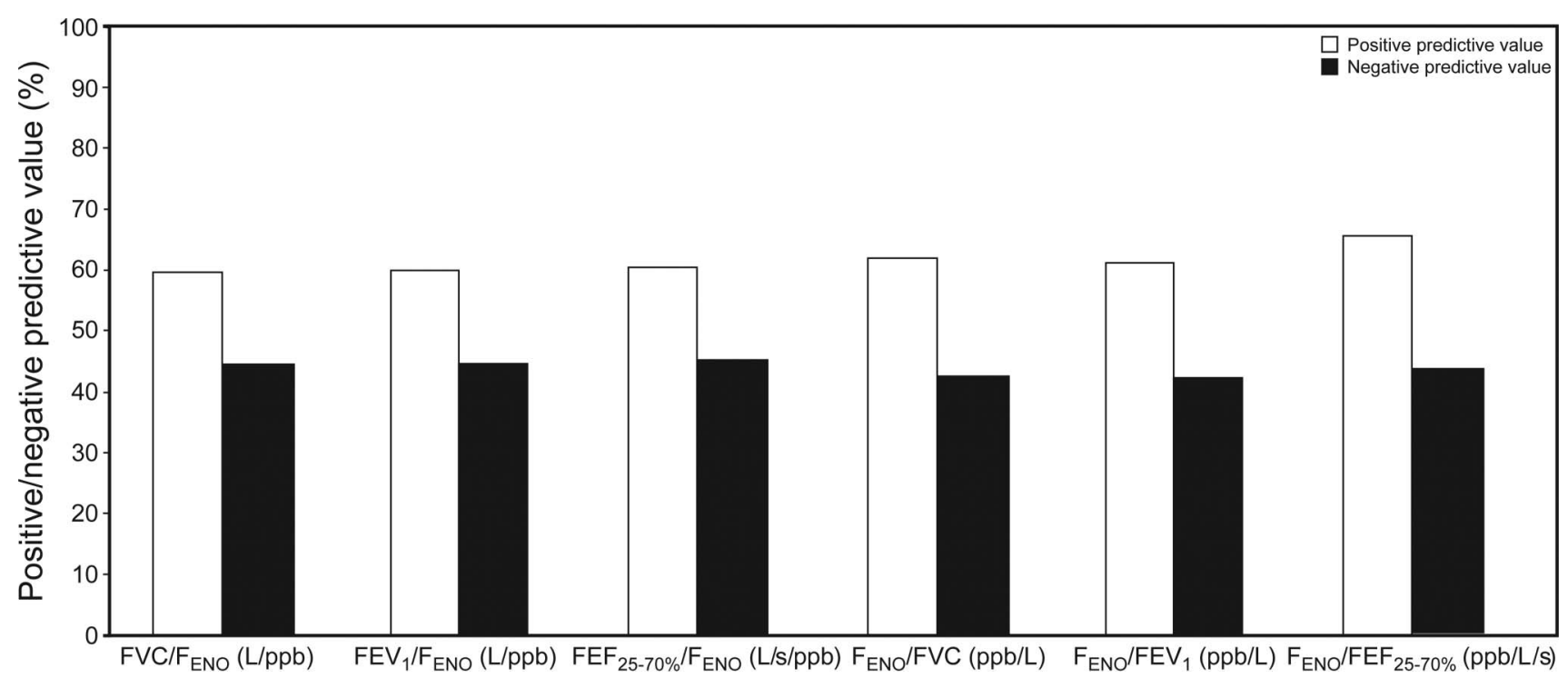

Fig. 6. Positive predictive values and negative predictive values for significant cutoff points computed for the study subjects with asthma. $\mathrm{F}_{\mathrm{ENO}}=$ fractional exhaled nitric oxide.

research. ${ }^{3,4,11}$ Dweik et al al ${ }^{2}$ emphasize that $\mathrm{F}_{\mathrm{ENO}}$ supports the diagnosis of asthma. ${ }^{2}$ The predictive values for $\mathrm{F}_{\mathrm{ENO}}$ were shown to be sufficiently robust to be used in this area; they are more reliable than peak expiratory flow and spirometry ${ }^{23}$ and similar to those associated with bronchial challenge tests. ${ }^{2,23-25}$ An increased $F_{E N O}$ value strengthens the basis for the diagnosis of asthma, principally because the airway inflammation in asthma is heterogeneous and is not always associated with increased $\mathrm{F}_{\mathrm{ENO}}$ (eg, neutrophillic airway inflammation); moreover, in subjects who have already been treated with inhaled steroids, the test may be falsely negative. ${ }^{2}$ Thus, the importance of
$\mathrm{F}_{\mathrm{ENO}}$ lies in its potential to identify steroid responsiveness rather than to make an apt clinical diagnosis. ${ }^{2}$ However, it is also known that $\mathrm{F}_{\mathrm{ENO}}$ may predict AHR; the measurements appear to reflect the dynamic interrelationships between the response to allergen or other triggers and evolving eosinophilic airway inflammation/AHR. ${ }^{2}$ Serial $\mathrm{F}_{\mathrm{ENO}}$ levels increase progressively in response to allergen exposure and the advent of airway symptoms. ${ }^{2}$ Due to practical difficulties involved in measuring AHR, especially in children, it was initially thought that $\mathrm{F}_{\mathrm{ENO}}$ might be used as a surrogate marker for AHR. The relationship between NO metabolism and AHR in asthma is complex ${ }^{2}$; some studies 
Table 4. Cutoff Points Due to the Analyzed Ratios in Study Subjects Diagnosed as Having Asthma Versus Healthy Subjects

\begin{tabular}{|c|c|c|c|c|c|c|c|c|c|c|c|}
\hline \multirow[b]{2}{*}{ Ratio } & \multicolumn{2}{|c|}{ Statistical Parameters } & \multicolumn{8}{|c|}{ Test Statistics } & \multirow[b]{2}{*}{$P$} \\
\hline & Mean $\pm \mathrm{SE}$ & $95 \% \mathrm{CI}$ & $\begin{array}{c}\text { Function of } \\
\text { Canonical } \\
\text { Structure }\end{array}$ & $\begin{array}{l}\text { Canonical } \\
\text { Correlation }\end{array}$ & $\begin{array}{l}\text { Eigen } \\
\text { Value }\end{array}$ & $\begin{array}{c}\text { Wilks } \lambda \\
\text { (Likelihood } \\
\text { Ratio) }\end{array}$ & $\begin{array}{c}\text { Sensitivity, } \\
\%\end{array}$ & $\begin{array}{c}\text { Specificity, } \\
\%\end{array}$ & $\begin{array}{c}\text { Positive } \\
\text { Predictive } \\
\text { Value, \% }\end{array}$ & $\begin{array}{l}\text { Negative } \\
\text { Predictive } \\
\text { Value, \% }\end{array}$ & \\
\hline $\mathrm{FVC} / \mathrm{F}_{\mathrm{ENO}}, \mathrm{L} / \mathrm{ppb}$ & $0.15 \pm 0.01$ & $0.15-0.16$ & -0.7 & 0.11 & 0.01 & 0.987 & 66.7 & 39.3 & 60.7 & 45.6 & .001 \\
\hline $\mathrm{FEV}_{1} / \mathrm{F}_{\mathrm{ENO}}, \mathrm{L} / \mathrm{ppb}$ & $0.13 \pm 0.004$ & $0.13-0.14$ & -0.8 & 0.12 & 0.01 & 0.986 & 66.7 & 39.3 & 60.7 & 45.6 & $<.001$ \\
\hline $\mathrm{FEF}_{25-75 \%} / \mathrm{F}_{\mathrm{ENO}}, \mathrm{L} / \mathrm{s} / \mathrm{ppb}$ & $0.15 \pm 0.01$ & $0.14-0.16$ & -0.8 & 0.13 & 0.02 & 0.983 & 65.4 & 42.0 & 61.3 & 46.3 & $<.001$ \\
\hline $\mathrm{F}_{\mathrm{ENO}} / \mathrm{FVC}, \mathrm{ppb} / \mathrm{L}$ & $11.1 \pm 0.3$ & $10.4-11.7$ & 0.8 & 0.013 & 0.02 & 0.984 & 34.9 & 70.9 & 62.8 & 43.6 & $<.001$ \\
\hline $\mathrm{F}_{\mathrm{ENO}} / \mathrm{FEV}_{1}, \mathrm{ppb} / \mathrm{L}$ & $12.6 \pm 0.4$ & $11.8-13.4$ & 0.8 & 0.13 & 0.02 & 0.983 & 33.5 & 70.9 & 61.8 & 43.1 & $<.001$ \\
\hline $\mathrm{F}_{\mathrm{ENO}} / \mathrm{FEF}_{25-75 \%}, \mathrm{ppb} / \mathrm{L} / \mathrm{s}$ & $12.0 \pm 0.4$ & $11.2-12.7$ & 0.8 & 0.13 & 0.02 & 0.983 & 34.0 & 75.6 & 66.2 & 44.9 & $<.001$ \\
\hline
\end{tabular}

Table 5. Cutoff Points Due to the Single Pulmonary Function Tests in Study Subjects Diagnosed as Having Asthma Versus Healthy Subjects

\begin{tabular}{|c|c|c|c|c|c|c|c|c|c|c|c|}
\hline \multirow[b]{2}{*}{ Ratio } & \multicolumn{2}{|c|}{ Statistical Parameters } & \multicolumn{8}{|c|}{ Test Statistics } & \multirow[b]{2}{*}{$P$} \\
\hline & Mean $\pm \mathrm{SE}$ & $95 \% \mathrm{CI}$ & $\begin{array}{l}\text { Function of } \\
\text { Canonical } \\
\text { Structure }\end{array}$ & $\begin{array}{c}\text { Canonical } \\
\text { Correlation }\end{array}$ & $\begin{array}{l}\text { Eigen } \\
\text { Value }\end{array}$ & $\begin{array}{l}\text { Wilks } \lambda \\
\text { (Likelihood } \\
\text { Ratio) }\end{array}$ & $\begin{array}{c}\text { Sensitivity, } \\
\%\end{array}$ & $\begin{array}{c}\text { Specificity, } \\
\%\end{array}$ & $\begin{array}{l}\text { Positive } \\
\text { Predictive } \\
\text { Value, \% }\end{array}$ & $\begin{array}{l}\text { Negative } \\
\text { Predictive } \\
\text { Value, \% }\end{array}$ & \\
\hline $\mathrm{F}_{\mathrm{ENO}}, \mathrm{ppb}$ & $25.7 \pm 0.7$ & $24.3-27.1$ & 0.8 & 0.11 & 0.01 & 0.988 & 77.7 & 32.7 & 33.8 & 76.9 & $<.001$ \\
\hline FVC, L & $2.0 \pm 0.03$ & $1.9-2.1$ & 0.3 & 0.06 & 0.003 & 0.997 & 41.8 & 60.0 & 31.6 & 70.0 & .10 \\
\hline $\mathrm{FEV}_{1}, \mathrm{~L}$ & $1.8 \pm 0.03$ & $1.7-1.8$ & 0.3 & 0.05 & 0.002 & 0.998 & 31.0 & 69.6 & 40.3 & 60.4 & .16 \\
\hline $\mathrm{FEF}_{25-75 \%}, \mathrm{~L} / \mathrm{s}$ & $2.00 \pm 0.03$ & $1.9-2.0$ & 0.1 & 0.02 & 0.0002 & 0.9997 & 29.0 & 68.3 & 36.1 & 60.9 & .63 \\
\hline
\end{tabular}

$\mathrm{F}_{\mathrm{ENO}}=$ fractional exhaled nitric oxide

$\mathrm{FEF}_{25-75 \%}=$ forced expiratory flow during the middle half of the $\mathrm{FVC}$ maneuver

have revealed that the relationships are inconsistent, and correlations are generally low. ${ }^{2}$ The clinical interpretation of $\mathrm{F}_{\mathrm{ENO}}$ in relation to AHR is even more problematic in subjects who are taking inhaled corticosteroids and with longstanding as opposed to recently developed asthma. ${ }^{2}$ Pathophysiological relationship studies show that AHR, airway inflammation, and $\mathrm{F}_{\mathrm{ENO}}$ belong to different domains. ${ }^{2}$ However, in one study in children, $\mathrm{F}_{\mathrm{ENO}}$ was used as a surrogate for AHR, and the data appeared to support its use in this limited context. ${ }^{25} \mathrm{We}$ also have showed lately that an elevated $\mathrm{F}_{\mathrm{ENO}}$ level increased the odds of exercise-induced bronchoconstriction in schoolchildren with asthma, independently of other asthma severity markers and the intensity of anti-asthma therapy. We conclude that it seems likely that the $\mathrm{F}_{\mathrm{ENO}}$ measurement may act as a screening test and help to prevent underdiagnosis and undertreatment of exercise-induced bronchoconstriction in schoolchildren with atopic asthma. ${ }^{3}$ Our previous results suggest that asthma-predicting $\mathrm{F}_{\mathrm{ENO}}$, defined in our study, could serve as a reliable tool to exclude asthma in schoolchildren. ${ }^{26}$ However, our results also indicated that all lung function parameters or $\mathrm{F}_{\mathrm{ENO}}$ should be interpreted in the context of gender, allergy profile, and co-morbidities in schoolchildren. ${ }^{26}$ Moreover, current studies show that the clinical implications of $\mathrm{F}_{\mathrm{ENO}}$ measurements in childhood asthma are unclear. ${ }^{2-4,26}$ Thus, in another study, ${ }^{11}$ we aimed at evaluating the relationship between the level of $\mathrm{F}_{\mathrm{ENO}}$, pre-bronchodilator $\mathrm{FEV}_{1}$, and the change in $\mathrm{FEV}_{1}$ after bronchodilator in children with asthma. Our results suggest that there is a need to measure $\mathrm{F}_{\mathrm{ENO}}$ before as well as after spirometry. ${ }^{11}$ Consequently, we also suggest assessing $\mathrm{F}_{\mathrm{ENO}}$ after short-acting $\beta_{2}$ agonist administration to children with asthma and bronchial obstruction. ${ }^{11}$ These study results are the reason why we provide the present analysis and especially attempt to fathom whether it is reasonable to use the $\mathrm{F}_{\mathrm{ENO}} / \mathrm{FEV}_{1}$, ratio or the other quotients included in our study, which could probably overcome doubts concerning the adequate measurement of inflammation using $\mathrm{F}_{\mathrm{ENO}}$. This is the problem that we and other researchers have emphasized. ${ }^{2,11}$

The main limitation of our study is its retrospective design. We gathered data from subjects' medical documentation, which could partly have influenced the accuracy of our results. The same could be true for the relatively wide range of the subjects' ages (4-24 y). However, all of the subjects remain under regular supervision of specialists in our clinic, including physical examination, 
lung function measurements, and other necessary tests, which excludes any doubts concerning the heterogeneity of diagnostic and therapeutic procedures. Therefore, all of the lung function tests were performed according to relevant guidelines. ${ }^{16-21}$ Another limitation was the lack of a replication population that would allow us to compare our results with the outcome obtained in that group. Our original methods should be tested with regard to the conventional way of diagnosing asthma and then tested again (ie, validated and standardized) in the population. There are no descriptive data provided for the reader to compare the disease state in the subjects with the professional literature. This is because the results received within the present study are totally novel. Thus, there is no possibility to compare them with the findings of any other authors.

\section{Conclusions}

To conclude, in our study, we defined new cutoff points for indicators (ratios), by which it may become possible to diagnose asthma on the basis of a patient's spirometry, $\mathrm{F}_{\mathrm{ENO}}$, and appropriate measures: $\mathrm{FVC} / \mathrm{F}_{\mathrm{ENO}}$, $\mathrm{FEV}_{1} / \mathrm{F}_{\mathrm{ENO}}, \quad \mathrm{FEF}_{25-75 \%} / \mathrm{F}_{\mathrm{ENO}}, \mathrm{F}_{\mathrm{ENO}} / \mathrm{FVC}, \mathrm{F}_{\mathrm{ENO}} / \mathrm{FEV}_{1}$, and $\mathrm{F}_{\mathrm{ENO}} / \mathrm{FEF}_{25-75 \%}$. Only $\mathrm{FEF}_{25-75 \%} / \mathrm{F}_{\mathrm{ENO}}$ and $\mathrm{F}_{\mathrm{ENO}} / \mathrm{FEF}_{25-75 \%}$ were significant predictors of any sensitization in the studied subjects. The described indicators, which significantly discriminated the study subjects in terms of the diagnosis of asthma, very strongly correlated with one another. We showed different cutoff points for the described ratios in the subjects with asthma versus the healthy ones and also different cutoff values in males versus females. We found higher sensitivity than specificity and higher positive predictive value than negative predictive value for such parameters as $\mathrm{FVC} / \mathrm{F}_{\mathrm{ENO}}, \mathrm{FEV}_{1} / \mathrm{F}_{\mathrm{ENO}}$, and $\mathrm{FEF}_{25-75 \%} / \mathrm{F}_{\mathrm{ENO}}$ and opposite results in terms of sensitivity versus specificity for the reverse ratios. However, the positive predictive values and negative predictive values were not clearly convincing with respect to diagnostic accuracy in the case of our original parameters. Therefore, we propose that these ratios eventually may become helpful and be used to overcome doubts concerning the adequate measurement of inflammation through $\mathrm{F}_{\mathrm{ENO}}$ in children, adolescents, and young adults. Nonetheless, one should always keep in mind that they do not appositely match the diagnostic accuracy. Respiratory resistance measured by the interrupter technique, specific $\mathrm{R}_{\mathrm{aw}}$, and $\mathrm{F}_{\mathrm{ENO}^{-}}$ combined parameters did not significantly correlate with the occurrence of asthma; the probable reason was their (respiratory resistance measured by the interrupter technique and specific $\mathrm{R}_{\mathrm{aw}}$ ) large dispersion. ${ }^{27} \mathrm{We}$ agree that clinical application of our ratios is not more convenient than that of other tests or bronchial reversibility. Therefore, finally, we claim that the use of $\mathrm{F}_{\mathrm{ENO}}$ for the diagnosis of asthma may not be an effective method and has also been acknowledged by asthma management guidelines. Physical examination, history, and spirometry and peak expiratory flow can diagnose asthma more accurately than our ratios. Clinically, our ratios may not prove to be more beneficial and feasible than lung function tests. We revealed these new spirometry/inflammatory and the opposite ratios being supportive for the universally used and recognized parameters in the process of diagnosing asthma. Although we believe that our new ratios may be helpful and can be used when one has doubts about whether spirometry is the only satisfactory measurement, reflecting indirectly the whole state of inflammation in the lungs of children with asthma, our results are not supported by/compared with any other study, and thus they demand further verification.

\section{REFERENCES}

1. Global Initiative for Asthma (GINA). GINA Report, Global Strategy for Asthma Management and Prevention. http://www.ginasthma.com/ guidelineitem.asp??11 $=2 \& 12=1 \&$ intId $=1561$. Accessed November 27, 2013.

2. Dweik RA, Boggs PB, Erzurum SC, Irvin CG, Leigh MW, Lundberg JO, et al. An official ATS clinical practice guideline: interpretation of exhaled nitric oxide levels (FENO) for clinical applications. Am J Respir Crit Care Med 2011;184(5):602-615.

3. Grzelewski T, Grzelewska A, Majak P, Stelmach W, Kowalska A, Stelmach R, Janas A, Stelmach I. Fractional exhaled nitric oxide (FeNO) may predict exercise-induced bronchoconstriction (EIB) in schoolchildren with atopic asthma. Nitric Oxide 2012;27(2):82-87.

4. Grzelewski T, Majak P, Jerzyńska J, Cichalewski L, Krakowiak J, Stelmach, et al. The association between fractional exhaled nitric oxide (FeNO) and cat dander in asthmatic children. Nitric Oxide 2011;25(3):288-293.

5. Hamid Q, Springall DR, Riveros-Moreno V, Chanez P, Howarth P, Redington A, et al. Induction of nitric oxide synthase in asthma. Lancet 1993;342(8886);1510-1513.

6. Redington AE, Meng QH, Springall DR, Evans TJ, Créminon C, Maclouf $\mathrm{J}$, et al. Increased expression of inducible nitric oxide synthase and cyclo-oxygenase- 2 in the airway epithelium of asthmatic subjects and regulation by corticosteroid treatment. Thorax 2001; 56(5):351-357.

7. Guo FH, Comhair SA, Zheng S, Dweik RA, Eissa NT, Thomassen $\mathrm{MJ}$, et al. Molecular mechanisms of increased nitric oxide (NO) in asthma: evidence for transcriptional and post-translational regulation of NO synthesis. J Immunol 2000;164(11):5970-5980.

8. Green RJ, Klein M, Becker P, Halkas A, Lewis H, Kitchin O, et al. Disagreement among common measures of asthma control in children. Chest 2013;143(1):117-122.

9. Strunk RC, Szefler SJ, Phillips BR, Zeiger RS, Chinchilli VM, Larsen $\mathrm{G}$, at al. Relationship of exhaled nitric oxide to clinical and inflammatory markers of persistent asthma in children. J Allergy Clin Immunol 2003;112(5):883-892.

10. Miraglia del Giudice M, Piacentini GL, Capasso M, Capristo C, Maiello N, Boner AL, Capristo AF. Formoterol, montelukast, and budesonide in asthmatic children: effect on lung function and exhaled nitric oxide. Respir Med 2007;101(8):1809-1813.

11. Grzelewski T, Majak P, Jerzyńska J, Stelmach W, Stelmach R, Janas A, et al. The interpretation of exhaled nitric oxide values in children with asthma depends on the degree of bronchoconstriction and the levels of asthma severity. Respir Care 2014;59(9):1404-1411. 
12. Bousquet J, Khaltaev N, Cruz AA, Denburg J, Fokkens WJ, Togias A, et al. Allergic Rhinitis and its Impact on Asthma (ARIA) 2008 update (in collaboration with the World Health Organization, GA(2)LEN and AllerGen). Allergy 2008;63(Suppl 86):8-160.

13. Silny W, Czarnecka-Operacz M, Gliński W, Samochocki Z, Jenerowicz D. Atopic dermatitis: contemporary view on pathomechanism and management: position statement of the Polish Dermatological Society specialists. Post Dermatol Alergol 2010;27:365-383.

14. American Thoracic Society. Recommendations for standardized procedures for the on-line and off-line measurement of exhaled lower respiratory nitric oxide and nasal nitric oxide in adults and children: 1999. Am J Respir Crit Care Med 1999;160(6):2104-2117.

15. Baraldi E, de Jongste JC, European Respiratory Society/American Thoracic Society (ERS/ATS) Task Force. Measurement of exhaled nitric oxide in children, 2001. Eur Respir J 2002;20(1):223-237.

16. Miller MR, Hankinson J, Brusasco V, Burgos F, Casaburi R, Coates A, et al. Standardisation of spirometry Eur Respir J 2005;26(2):319338.

17. Miller MR, Crapo R, Hankinson J, Brusasco V, Burgos F, Casaburi $\mathrm{R}$, et al. General considerations for lung function testing Eur Respir J 2005;26(1):153-161.

18. Pellegrino R, Viegi G, Brusasco V, Crapo RO, Burgos F, Casaburi $\mathrm{R}$, et al. Interpretative strategies for lung function tests. Eur Respir $\mathrm{J}$ 2005;26(5):948-968.

19. Wanger J, Clausen JL, Coates A, Pedersen OF, Brusasco V, Burgos $\mathrm{F}$, et al. Standardisation of the measurement of lung volumes. Eur Respir J 2005;26(3):511-522.
20. Merkus PJ, Mijnsbergen JY, Hop WC, de Jongste JC. Interrupter resistance in preschool children: measurement characteristics and reference values. Am J Respir Crit Care Med 2001;163(6):1350-1355.

21. Klug B, Bisgaard H. Measurement of the specific airway resistance by plethysmography in young children accompanied by an adult. Eur Respir J 1997;10(7):1599-1605.

22. Assessing your weight. Atlanta, Georgia: Centers for Disease Control and Prevention. http://www.cdc.gov/healthyweight/assessing/ index.html. Accessed February 25, 2014.

23. Smith AD, Cowan JO, Filsell S, McLachlan C, Monti-Sheehan G, Jackson P, Taylor DR. Diagnosing asthma: comparisons between exhaled nitric oxide measurements and conventional tests. Am J Respir Crit Care Med 2004;169(4):473-478.

24. Deykin A, Massaro AF, Drazen JM, Israel E. Exhaled nitric oxide as a diagnostic test for asthma: online versus offline techniques and effect of flow rate. Am J Respir Crit Care Med 2002;165(12):1597-1601.

25. Berkman N, Avital A, Breuer R, Bardach E, Springer C, Godfrey S. Exhaled nitric oxide in the diagnosis of asthma: comparison with bronchial provocation tests. Thorax 2005;60(5):383-388.

26. Grzelewski T, Witkowski K, Makandjou-Ola E, Grzelewska A, Majak P, Jerzyńska J, et al. Diagnostic value of lung function parameters and FeNO for asthma in schoolchildren in large, real-life population. Pediatr Pulmonol 2014;49(7):632-640.

27. Klug B, Nielsen KG, Bisgaard H. Observer variability of lung function measurements in 2-6-yr-old children. Eur Respir J 2000;16(3): 472-475. 